\title{
Immunohistochemical profile of breast cancer patients on oncology department, Moewardi Hospital, Surakarta, Indonesia
}

\author{
Dian Ibnu Wahid ${ }^{1}$, KristantoYuli Yarsa ${ }^{2}$ \\ ${ }^{1}$ General Surgery Resident Moewardi Hospital, ${ }^{2}$ Oncology Department Moewardi \\ Hospital, Surakarta, Indonesia
}

DOI: http://dx.doi.org/10.19106/JMedScieSup0050012018016

\section{ABSTRACT}

Immunohistochemical is used to show hormone receptors on their surface. The aim of this study were to find information about immunohistochemical profile of breast cancer patient on oncology department, Moewardi Hospital, Surakarta Indonesia. A total of 1.395 cases of breast carcinoma with HER2 profile were reviewed. The mean age of the patients was 45.7 (Ranged 23-73 years old). At time of diagnosis 739 (53\%) patients were under 50 years of age. The frequency of HER2 positive was higher in this group than other. The incidence of patients above 50 years of age were significancy higher in HER2 positive with 363 (47\%). Ductal invasive carcinoma was the most common type of breast carcinoma (86.9\%). HER-2 Positive subtype was the most common subtype in the woman breast carcinoma (43.6\%), which was followed by basal like (31.3\%), luminal A $(16.8 \%)$ and (8.3\%). The highest tumor grading, was G3 with the results $764(54.7 \%)$. G3 got the highest results on HER2 positive with 535. We just divide the type of tumor consist of three parts (ductal, lobular, and other). In tumor type obtained the most data on ductal carcinoma with 878 (63\%).

Keyword: immunohistochemical profile - breast cancer

*corresponding author: diw18@yahoo.com 